Scenario-Based Training for Sexual Harassment Prevention

\author{
David Desplaces \\ Tommy and Victoria Baker School of Business, The Citadel \\ John Ogilvie \\ Barney School of Business, University of Hartford
}

\begin{abstract}
Author Note
David Desplaces, Professor of Strategy and Entrepreneurship

John Ogilvie, Professor of Management

Correspondence concerning this article should be addressed to David Desplaces, Professor of Strategy and Entrepreneurship, Tommy and Victoria Baker School of Business, The Citadel, 171 Mountrie Street, Charleston, SC 29409. Email: ddesplac@ citadel.edu
\end{abstract}




\begin{abstract}
Although laws have been enacted both to prevent sexual harassment $(\mathrm{SH})$ and to prosecute those who engage in it, the issue remains a matter of concern in the workplace. A variety of training programs have been developed to address $\mathrm{SH}$, but their effectiveness has been called into question. Using a scenario-based activity, we directly assessed the impact of various training approaches on undergraduate and graduate students' perceptions of SH. A comparison of preand post-measures indicated that the scenario and associated activities yielded post-session shifts in awareness of SH. Differences were found between undergraduate men and women and between undergraduates and graduates, with no gender differences observed among the latter.
\end{abstract}

Keywords: Case study, Human Resource Management, Legal, Management, Scenario, Sexual Harrassment

\title{
Scenario-Based Training for Sexual Harassment Prevention
}

In a study conducted in 2002, 97\% of firms surveyed had an explicit policy statement on sexual harassment $(\mathrm{SH})$, and $62 \%$ offered training intended to prevent and combat it (Blackman, 2005; Tyner \& Clinton, 2010). Some states, among them Connecticut and California, mandate SH training for supervisors, and many companies and universities conduct regular programs designed to address the problem. Nevertheless, it is estimated that some 40-75\% of women and 13-31\% of men in the United States experience SH (Aggarwal \& Gupta, 2000; Quick \& McFadyen, 2017). Even in a study of human resource professionals, $89 \%$ self-reported gender discrimination, and 47\% unwanted sexual attention (Tyner \& Clinton, 2010). Particularly troubling is the indication in research conducted by Cheung and colleagues (2017) that cynical attitudes toward sexual harassment might effect the outcome of training. Which in our eyes should raise awareness on the part of organizations that have not fully committed to establishing and maintaining an environment and culture free of SH. The revelations brought about by the \#metoo movement have further fueled this cynicism by making clear that $\mathrm{SH}$ remains a significant issue in all types of organizations. While many cases continue to go unreportedmeaning that the official EEOC numbers represent an underestimate of the true extent of the problem - the effort put into awareness training does offer some hope that it is possible to build a society that is not plagued by SH.

The present study begins with a review of the $\mathrm{SH}$ literature, with attention to the types of sexual harassment, their emotional and economic impact, and, especially, the effectiveness of SH awareness training. We next describe our attempts to measure the effectiveness of this training using a scenario activity. The study concludes with a discussion of the implications of the findings and avenues for further research. 


\section{Defining Sexual Harassment}

The US Supreme Court recognized in 1986 what constitutes a hostile work environment and the responsibility that an employer bears in sexual harassment claims. More specifically, the case stated:

To prove a hostile environment claim based on sexual harassment under current law, harassing conduct must be unwelcome, "because of...sex," (US Court Case: 42 U.S.C.A. § 2000e-2(a)(1) (West 1991); Oncale v. Sundowner Offshore Servs., Inc., 523 U.S. 75, 79-80 (1998).) and "sufficiently severe or pervasive to alter the conditions of the victim's employment and create an abusive working environment."(US Court Case: Meritor, 477 U.S. at 67.) The environment must be both subjectively offensive to the victim and also objectively offensive to a reasonable person. (US Court Case: Id. at 21-22.) The employer is responsible for the hostile work environment if it knew or should have known about the harassment and failed to take proper action. (US Court Cases: 29 C.F.R. § 1604.11(d) (1997) and Meritor Savings Bank, FSB v. Vinson, 477US 57, 1986)

To appreciate the prevalence and deleterious effects of SH in the workplace fully, it is important first to define the relevant terms clearly. In the literature on the topic, two broad dimensions of SH must be distinguished, a legal one and a psychological one (O'Leary-Kelly, Bowes-Sperry, Bates, \& Lean, 2009; Willness, Steel, \& Lee, 2007). The U.S. Equal Employment Opportunity Commission (2002) defines SH legally in the following terms:

Unwelcome sexual advances, requests for sexual favors, and other verbal or physical conduct of a sexual nature constitute sexual harassment when this conduct explicitly or implicitly affects an individual's employment, unreasonably interferes with an individual's work performance, or creates an intimidating, hostile, or offensive work environment.

This legal definition comprises several components, which might lead to different types of sexual harassment. There is, to begin with, the fairly clear and objective definition involving a quid pro quo in which an individual might feel pressured to grant sexual favors in exchange for remaining employed or receiving a promotion. Less direct and explicit is the creation of a hostile work environment that impairs an employee's ability to perform, for instance, through the telling of sexually-oriented stories or jokes (including based on one's sex), the display of sexually charged images, or comments on workers' physical appearance. Those who engage in such behavior may be unaware that they are making it difficult for others to perform their jobs and to advance. An observer of the harassment of a fellow worker may also contribute to a hostile environment, as can be seen in the case study presented below. Although we want to acknowledge that much still needs to be done to clarify or define the types of $\mathrm{SH}$, we have chosen to focus on its traditional sense that is harassment that is sexual in nature that is unwelcome.

Most researchers also acknowledge a behavioral or psychological aspect of SH that transcends this relatively narrow legal framework, defining it as, for example, "unwanted sexrelated behavior at work that is appraised by the recipient as offensive, exceeding her resources, 


\section{SCENARIO-BASED TRAINING FOR SH PREVENTION}

or threatening her well-being" (Fitzgerald, Swan, \& Magley, 1997, p. 15). This definition is broader than the legal one, touching on gender discrimination, unwanted sexual attention, and sexual coercion (Fitzgerald, Drasgow, Hulin, Gelfand, \& Magley, 1997; Willness et al., 2007).

Psychological harassment can resemble bullying when it takes the form of gender discrimination, in that it involves intimidation and hostility, but it need not meet the legal, reasonable person standard to have an impact. Indeed, such behavior may not even be overtly sexual to be perceived as hostile and demeaning. Some scholars have connected harassment specifically with misogynistic attitudes. Thus Taylor (1988) and Fitzgerald et al. (2007) have argued that harassment is more a manifestation of hostility toward women than of any desire for sexual gratification. This latter distinction deserves to be developed and included in SH harassment-training programs.

\section{Impact of Sexual Harassment}

The consequences of $\mathrm{SH}$ for those who have subject to it are substantial, as the \#metoo movement has revealed. A meta-analysis has identified negative psychological outcomes for individuals as well as negative impacts on organizations associated with SH (Willness et al., 2007). Victims of SH have reported anxiety, depression, emotional distress, interpersonal friction, career setbacks, family problems, and sexual dysfunction (Barak, 1994; McLaughlin, Uggen, \& Blackstone, 2017; Willness, et al., 2007). Organizational outcomes for workers may include such withdrawal behaviors as absenteeism and turnover, decreased job satisfaction and organizational commitment, and decreased productivity (Taylor, 1988; Willness et al., 2007). The breadth of the organizational impact is in part because the adverse outcomes extend beyond the victims to include coworkers and other observers of SH (O'Leary-Kelly et al., 2009). Moreover, clients and customers may be implicated in the negative impacts of SH (Gettman \& Gelfand, 2007).

Beyond such impacts felt by individuals and organizations, $\mathrm{SH}$ is associated with high financial costs, in particular relating to litigation and settlement payments. Indirect adverse financial impacts have also been documented; specifically Willness et al. (2007), using utility analyses, reported losses in productivity owing to $\mathrm{SH}$, with the costs to organizations estimated at some $\$ 22,500$ per individual affected.

From the perspective advanced in the present study, training constitutes the most effective means for preventing SH. It is also cost-effective, in the long run requiring only a fraction of the investment of time and monetary resources that are currently being spent on a per person basis dealing with $\mathrm{SH}$ in the ways just described.

\section{The Effectiveness of Sexual Harassment Training}

In the United States, efforts to combat $\mathrm{SH}$ through training have become widespread, with as many as nine in ten employers offering it across all industries (Bainbridge, Perry, \& Kulik, 2018). The cost of this training to U.S. employers has been estimated at more than 10 billion dollars annually (Goldberg, 2011), and, not surprisingly, the usefulness of this enormous outlay has been called into question. Nevertheless, multi-level engagement of this sort has emerged as the key recommendation for efforts to combat $\mathrm{SH}$, including the use of interactive 


\section{SCENARIO-BASED TRAINING FOR SH PREVENTION}

and experiential methods (Becton, Gilstrap, \& Forsyth, 2017). Given the prevalence of SH and its harmfulness in the workplace, as was seen above, as well as the expense of the training, the effectiveness of the various methods, including interactive (scenario-based) ones, is naturally a major concern.

In fact, the research teams of Salas, Wildman, and Piccolo (2009) and Buchanan, Settles, Hall, and O'Connor (2014) have both found simulation-based learning to be superior to other training strategies in terms of imparting knowledge about SH and creating empathy towards its victims. Such evidence immediately raises the question of the types of scenarios or simulations that would best serve as the basis for the training. Again, however, there has been little work comparing the effectiveness of various types of scenarios in SH training. Furthermore, Ebner and Efron (2005) have argued that:

the potential danger of workshop deterioration increases when the simulation game centers on a situation about which many or all of the participants may have powerful preconceptions, such as an issue that is important to participants in their real lives or one that has been widely covered by the media for an extended period of time. (p. 380)

These researchers went on to identify sexual harassment complaints specifically as one cause of such deterioration. Thus quid pro quo scenarios could elicit strong emotions that would hinder rather than promote learning, especially for participants who have experienced this type of $\mathrm{SH}$. Such scenarios would also easy for participants to recognize and, therefore would not occasion much debate. Scenarios built around more subtle and less obvious settings, by contrast, might prove to be a more effective tool for discussion and learning about $\mathrm{SH}$.

Scenarios have been used in several settings for training purposes, including to teach auditors to determine when assets have been misallocated (Strand, Welch, Holmes, \& Judd, 2002), contextual factors in conflict management (Callanan \& Perri, 2006), and organizational justice issues in performance reviews (Tatum \& Eberlin, 2006). Furthermore, scenarios about handling difficult situations have shown to enhance the reading scores of students in grades 6 to 8 (Juzwik, Nystrand, Kelly, \& Sherry, 2008). Such findings suggest that a carefully crafted scenario involving $\mathrm{SH}$ issues could prove effective in raising awareness of the problem in the workplace. We accordingly formulated Hypothesis 1 as follows:

H1: Training scenarios and associated discussions can improve awareness of SH.

\section{Gender Differences in Perceptions of SH}

A further significant issue regarding $\mathrm{SH}$ is whether women and men perceive it differently. Since women are more frequently the objects of harassing behaviors, any such differences should be taken into account during training. Informative in this respect, are several meta-analyses that have aggregated results from multiple studies. To begin with, Blumenthal (1998) found that women, in general, perceive wider range behavior to constitute harassment than men do; he did not, however, identify any moderating factors relating to specific situations. In another meta-analysis, Rotondo, Nguyen, \& Sackett (2001) found that perceptions diverged more greatly between men and women as situations became more ambiguous, for instance, 


\section{SCENARIO-BASED TRAINING FOR SH PREVENTION}

concerning dating pressure and derogatory attitudes. Another study, however, using scenarios involving a male and female employee within the same organization, did not find any differences in perceptions of harassment attributable to gender (Dougherty, Turban, Olson, Dwyer, \& LaPreze, 1996).

The literature is thus inconsistent on this point, but we found more convincing evidence that women are more likely to perceive that a given act constitutes SH than men. We accordingly formulated Hypothesis 2 as follows:

H2: Women tend to be more sensitive to $\mathrm{SH}$ in the context of a given scenario than men.

\section{The Effectiveness of Training Intended to Change Attitudes}

Initial approaches to addressing the problem of SH involved the presentation of relevant information, for instance, in the context of seminars (Barak, 1994; Paludi \& Barrickman, 1991). In one informative study, Christian and Gumbus (2009) used the Society for Human Resource Management guidelines to help students learn about a potential case of SH. Published arbitration cases may also be an effective means of teaching about the subject (Lucero, 2007), as concrete conclusions can be drawn from arbitration decisions.

Again, however, there has been relatively little research assessing the efficacy of these approaches. Nevertheless, a general consensus has emerged in the academic community that more active modes of engagement yield better learning outcomes. In one of the few informative studies that have appeared, Beauvais (1986) used videotaped samples or scenarios to provoke discussion and then followed up with role-playing, methods that eventually deepened participants' understanding and catalyzed shifts in their attitudes about harassment. Barak (1994) likewise combined videotaped scenarios with role-playing to improve understanding and to teach skills for coping with $\mathrm{SH}$, in this case, using a female-only sample (but not pre- and postmeasures). In still another study, Dunlop and Lee (2004), showed one group of subjects videos of $\mathrm{SH}$ vignettes and provided another with educational literature on the subject; unlike Beauvais and Barak, however, these latter researchers found that the literature intervention yielded a greater change in perceptions than the video intervention. This result may be attributable to the greater effort required to read than to watch a videotape; similarly, cognitive dissonance research has shown that low financial incentives can yield greater changes in attitude than larger ones (Festinger \& Carlsmith, 1959). More research is necessary to resolve the issue.

These approaches all assume that, once participants become aware of what constitutes $\mathrm{SH}$, its legal consequences, and institutional policies for preventing it, they will "do the right thing." This assumption may, however, be dependent on the composition of the sample. Thus Sipe, Johnson, and Fisher (2009) found that undergraduates did not feel threatened by SH in the workplace, while Dougherty et al. (1996) found that graduates tended to view harassing behaviors more negatively than undergraduates. This apparent gap between more experienced (in this case, the graduates) and less experienced (the undergraduates) individuals in the workplace deserve further investigation, and we, therefore, formulated Hypothesis 3 as follows:

H3: Graduate students tend to be more aware of SH than undergraduates. 


\section{Methodology}

\section{Respondents}

We used this scenario in an undergraduate and a graduate class (total of 10 sections) taught at a university in the northeastern United States that covered the topics of management, organizational behaviors, human resources, and leadership. Our convenience sample of 223 students consisted of 147 undergraduates, and 76 graduate students (working professionals studying part-time) allowed us to compare less experienced students (undergraduates) with more experienced working professionals (graduate students). Furthermore, it allowed us to group individuals with training and more experience with the topic (graduate students were working professionals versus traditional undergraduates studying full time with limited to no work experience). In terms of gender, $74 \%$ of the participants were male, and $27 \%$ female.

\section{Scenario}

A brief (one-page) scenario was presented to the participants following Desplaces and Ogilvie (2013). In this scenario, questions were raised regarding the actions of a manager toward a customer regarding the creation of a hostile environment for the employees. The issues were not straightforward, requiring a relatively deep understanding of $\mathrm{SH}$ and the articulation of justification for actions to be taken by management. This scenario was deemed particularly wellsuited for the present study in light of the evidence, alluded to above, that the behavior of customers toward employees can have a considerable impact (Gettman \& Gelfand, 2007), the problem is especially acute in the entertainment industry (Williamson, 2006).

\section{Instrument}

A brief quantitative survey was administered to the participants before and after a class discussion. This survey used a five-point scale ranging from 1, indicating strong disagreement, to 5 , indicating strong agreement. The items included in the survey instrument had been developed specifically for this scenario by the authors and designed to assess perceptions of key SH topics as reported in the literature (e.g., flirting and legal interpretations of $\mathrm{SH}$ ) as well as to measure the possible impact of the scenario (i.e., change in perceptions of having witnessed SH). The same instrument was used to assess the impact of the scenario on the participants' understanding of sexual harassment.

\section{Analysis}

We analyzed the survey results comparing the various groups (undergraduate, graduate) using SPSS software (Tables 1-5). As seen in Table 1, there were no significant differences between undergraduate and graduate participants in terms of having witnessed SH, and both groups revised their assessments of the severity of the $\mathrm{SH}$ in the scenario downward after completing the exercise and participating in the debriefing discussion. These data indicate that participants may have considered certain behaviors or actions to be $\mathrm{SH}$ that were not so classified during the discussion of the scenario, a finding that stresses the importance of training. 


\section{SCENARIO-BASED TRAINING FOR SH PREVENTION}

\section{Table 1}

Difference in Status in Terms of Training and Witnessing Sexual Harassment

\begin{tabular}{|c|c|c|c|c|c|c|c|}
\hline \multicolumn{4}{|c|}{ Time 1} & \multicolumn{4}{|c|}{ Time 2} \\
\hline \multicolumn{2}{|c|}{ Yes } & \multicolumn{2}{|c|}{ No } & \multicolumn{2}{|c|}{ Yes } & \multicolumn{2}{|c|}{ No } \\
\hline Under. & Grad. & Under. & Grad. & Under. & Grad. & Under. & Grad. \\
\hline $39.6 \% *$ & $62.2 \% *$ & $60.4 \% *$ & $37.8 \% *$ & & & & \\
\hline $50 \%$ & $49.3 \%$ & $50 \%$ & $50.7 \%$ & $43.3 \%$ & $42.4 \%$ & $56.7 \%$ & 57.6 \\
\hline
\end{tabular}

*Chi-square shows probable difference between groups

The findings further indicate that individuals' interpretations of SH situations could become more nuanced as a result of discussion and facilitation. Further analysis using a paired ttest comparison of pre- and post-tests (Table 2) showed that the scenario and its discussion had a significant impact on the perception that sexual attention at work is never appropriate (mean $=$ 3.85 before the discussion and 4.07 afterward). Although the responses still fell between disagreeing and disagreeing strongly, there was a marginal change in the perception that the manager's action was appropriate in the particular context of the scenario (specifically, the mean of 1.49 increased to 1.61). A marginal change was also noticed in participants' recognition of the need for management to take further action. Further analysis comparing pre- and post-test results among undergraduates and graduates demonstrated that the former were most significantly affected regarding the perception that sexual attention at work is never appropriate $(m e a n=3.72$ for the pre-test and 3.99 for the post-test) and that management needed to take further action (increase in the mean from 3.94 to 4.21). These results support Hypothesis 1, indicating that the scenario and associated discussion had a positive impact on the participants' perceptions. 


\section{Table 2}

Comparison of Pre- and Post-Test

\begin{tabular}{|c|c|c|c|c|c|}
\hline \multicolumn{2}{|c|}{ General } & \multicolumn{2}{|c|}{ Underg. } & \multicolumn{2}{|c|}{ Grad. } \\
\hline Time & Time & Time & Time & Time & Time \\
\hline $\begin{array}{l}8 \\
8 \\
3 \\
2 \\
2\end{array}$ & $\begin{array}{l}8 \\
80 \\
0 \\
\vdots \\
2\end{array}$ & 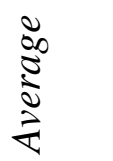 & 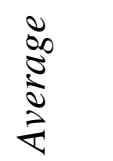 & 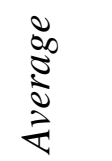 & $\begin{array}{l}8 \\
8 \\
\frac{0}{2} \\
\frac{\pi}{2}\end{array}$ \\
\hline 1.49 & $1.61 * *$ & 1.53 & 1.64 & 1.42 & 1.56 \\
\hline 2.62 & 2.76 & 2.72 & 2.73 & 2.43 & $2.80 *$ \\
\hline 3.73 & 3.62 & 3.72 & 3.66 & 3.74 & 3.56 \\
\hline 2.49 & 2.38 & 2.60 & 2.54 & 2.27 & 2.14 \\
\hline 2.89 & 2.90 & 2.95 & 2.76 & 2.78 & 3.12 \\
\hline 3.85 & $4.07 *$ & 3.72 & $3.99 *$ & 4.09 & 4.18 \\
\hline 4.04 & $4.17 * *$ & 3.94 & $4.21 *$ & 4.22 & 4.11 \\
\hline 3.44 & 3.49 & 3.46 & 3.46 & 3.39 & 3.55 \\
\hline
\end{tabular}

1. The actions or behaviors of the manager are appropriate in this context.

2. Flirting with customers is different from the same type of attention directed at employees

3. Most people are offended by sexual comments or jokes in the workplace.

4. Most sexual harassment is consciously or unconsciously encouraged by the "target."

5 . The actions or behaviors of the manager are illegal.

6. Sexual attention at work is never appropriate.

7. Management should take some remedial action toward the manager 8. This situation constitutes sexual harassment.

Significance: *less than 0.05 level, **less then 0.10 level

Table 3 confirms the discrepancy in this regard between men and women, with $44.5 \%$ of the former and $55.5 \%$ of the latter reporting having witnessed such behaviors. Nevertheless, the men who participated in the study appear to have responded to the exercise and discussion by narrowing their definitions of sexual harassment, showing a significant drop from $44.5 \%$ to $35 \%$ between the pre- and post-test discussions. 


\section{SCENARIO-BASED TRAINING FOR SH PREVENTION}

\section{Table 3}

\section{Gender Differences Relating to Training and Witnessing Sexual Harassment}

\begin{tabular}{|c|c|c|c|c|c|c|c|c|}
\hline \multirow[b]{4}{*}{$\begin{array}{l}\text { Have you had any } \\
\text { form of sexual } \\
\text { harassment training? }\end{array}$} & \multicolumn{4}{|c|}{ Time 1} & \multicolumn{4}{|c|}{ Time 2} \\
\hline & \multicolumn{2}{|c|}{ Yes } & \multicolumn{2}{|c|}{ No } & \multicolumn{2}{|c|}{ Yes } & \multicolumn{2}{|c|}{ No } \\
\hline & Male & Female & Male & Female & Male & Female & Male & Female \\
\hline & $50.4 \%$ & $43.7 \%$ & $49.6 \%$ & $56.3 \%$ & & & & \\
\hline $\begin{array}{l}\text { Have you witnessed } \\
\text { behaviors or actions } \\
\text { that you define as } \\
\text { sexual harassment? }\end{array}$ & $44.5 \% *$ & $56.3 \% *$ & $55.5 \% *$ & $43.7 \% *$ & $35,0 \% *$ & $54.1 \% *$ & $65.0 \% *$ & $45.9 \% *$ \\
\hline
\end{tabular}

*Chi-square shows probable difference between groups

Some adult female students argued during the discussions that a woman should be able to dress somewhat provocatively without attracting this type of attention. Other participants argued that salespeople often use flirtation to sell products and services. Such perceptions were confirmed by our survey (Table 4$)$, in which men were found to be moderately $(p<.10)$ more likely to distinguish flirting with customers from the same type of attention directed at employees. Our results also indicate that men were more likely to view SH as consciously or unconsciously encouraged by the "target" (2.62 compared with 2.31). Women, moreover, differed significantly from the men in both pre- and post-exercise surveys regarding whether sexual attention at work is appropriate. Therefore, Hypothesis 2 was supported.

The responses of the graduate student participants to these questions, on the other hand, did not change from the pre- to the post-test, as shown in Table 5. Thus an examination of preexercise responses showed a significant difference $(p<.05)$ on three of the questions $(4,6$, and 7 ) on an independent simple t-test comparing the responses of the two groups. Graduate participants were more likely to disagree with the notion that most sexual harassment is consciously or unconsciously encouraged by the "target" (mean $=2.27$ ) than undergraduate participants (mean $=2.60$ ). This question was the only source of differences in the post-exercise responses (mean for graduates $=2.14$; for undergraduates, 2.54 ). The graduate participants appeared to be more sensitive to the appropriateness of sexual attention (mean of 4.09 compared with 3.72 for the undergraduates) and the need for management to take action in the case described in the scenario (mean of 4.22 compared with 3.94 for the undergraduates). Furthermore, the graduate students were marginally $(p<.10)$ more likely to perceive the action of the manager to be illegal after participation in the discussion than undergraduates (mean of 3.12 compared with 2.76 ). Thus a drastic change occurred from the pre-test, on which they were less likely to perceive the behaviors to be illegal (mean of 2.78 compared with 2.95). The fact that $64 \%$ of undergraduate participants, compared with $31 \%$ of the graduates, had received no sexual harassment training further lend support to Hypothesis 3 that graduates or professionals are more aware. 


\section{Table 4}

\section{Comparison of Reactions Across Gender}

Questionnaire

1. The actions or behaviors of the manager are appropriate in this context.

2. Flirting with customers is different from the same type of attention directed at employees.

3. Most people are offended by sexual comments or jokes in the workplace.

4. Most sexual harassment is consciously or unconsciously encouraged by the "target."

5. The actions or behaviors of the manager are illegal.

6. Sexual attention at work is never appropriate.

7. Management should take some remedial action towards the manager.

8. This situation constitutes sexual harassment.

\section{Time 1}
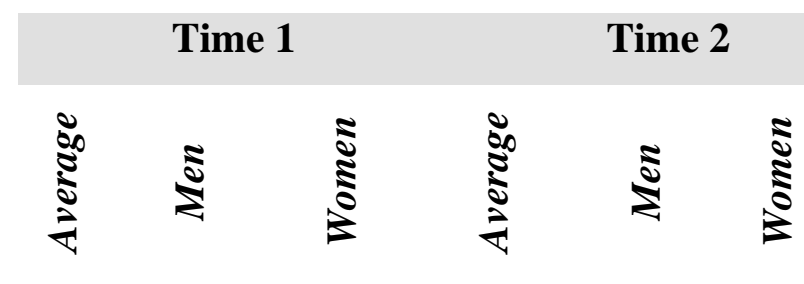

$\begin{array}{llllll}1.49 & 1.55 & 1.40 & 1.61 & 1.67 & 1.50\end{array}$

$2.62 \quad 2.73 * * \quad 2.45 * * \quad 2.76 \quad 2.87 \quad 2.63$

$\begin{array}{llllll}3.73 & 3.71 & 3.75 & 3.62 & 3.49 & 3.74\end{array}$

$2.49 \quad 2.62 * \quad 2.31 * 2.38 \quad 2.44 \quad 2.26$

$\begin{array}{llllll}2.89 & 2.82 & 3.05 & 2.90 & 2.89 & 2.85\end{array}$

$3.853 .71 * \quad 4.05 * 4.07 \quad 3.92 * 4.22 *$

$\begin{array}{llllll}4.04 & 4.01 & 4.09 & 4.17 & 4.11 & 4.21\end{array}$

$\begin{array}{llllll}3.44 & 3.42 & 3.51 & 3.49 & 3.37 & 3.59\end{array}$

Significance: *less then 0.05 level, **less than 0.10 level comparing genders 


\section{SCENARIO-BASED TRAINING FOR SH PREVENTION}

\section{Table 5}

Comparison of Responses of Undergraduates and Graduates

Questionnaire
1. The actions or behaviors of the manager are appropriate in this context.

2. Flirting with customers is different than the same type of attention directed at employees.

3. Most people are offended by sexual comments or jokes in the workplace.

4. Most sexual harassment is consciously or unconsciously encouraged by the "target."

5 . The actions or behaviors of the manager are illegal.

6. Sexual attention at work is never appropriate

7. Management should take some remedial actions toward the manager.

8. This situation constitutes sexual harassment.
Time 1

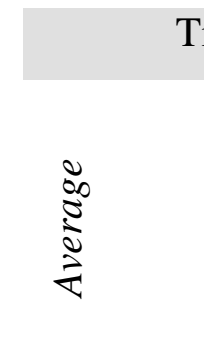

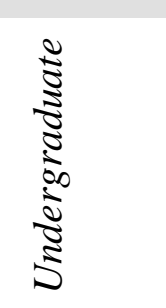

1.49

1.53

2.62

3.73

2.49

2.89

3.85

4.04

3.44

$* p<0.05$

In our scenario, however, the more likely victims of harassment were the two employees (one male and one female) who observed the incident, though students rarely identified them as such during the group discussions. As noted earlier, Gettman and Gelfand (2007) have argued that bystanders can be impacted by viewing the harassing behaviors of managers. The comments of the manager in the scenario thus had the potential to create a sexually charged and potentially hostile environment for the two employees. Such a workplace could be considered offensive by the customer, who was the object of the sexual reference as well. Current definitions of SH in state and federal statutes pertain only to the workplace, so any interaction between the manager and the customer, although inappropriate, would not constitute SH. This limitation does not mean that customers could not take subsequent legal action in the form of lawsuits.

Certain interpretations of the law have also stressed patterns of behavior. Because the incident in the scenario was isolated and the customer did not object, it is unlikely that the behavior would meet a legal definition of harassment. We note that the phenomenon of sudden-onset SH (Woodford \& Woodford, 2005) does not seem relevant here, for it involves severe incidents, unlike the situation described in the scenario. However, it is important to note that patterns of behavior are not necessary to warrant SH claims and that the law does recognize an isolated incident based on the severity. 


\section{SCENARIO-BASED TRAINING FOR SH PREVENTION}

\section{Conclusions}

Several studies have suggested that the situation in which an incident of harassment occurs impacts reactions by those involved (Stockdale, Vaux, \& Cashin, 1995; O'Connor, Gutek, Stockdale, Geer, \& Melancon, 2004). Attention to the more subtle circumstances of a manager acting inappropriately toward a customer, as in the scenario used in the present study, thus holds promise in terms of changing attitudes and behavior. Our analysis showed the scenario to be effective in giving the participants in our study a better understanding of SH. We did not, however, through this study attempt to influence actual behavior. Future research efforts in professional settings, across industries, and/or types of professionals with different educational backgrounds might further shed light on how attitudes and behaviors can be altered or improved.

Although the findings presented here reinforce the significance of training and experience when it comes to recognizing, preventing, and dealing with $\mathrm{SH}$, it is important to the point that it is not enough for organizations to provide training for their members. What is needed are systems in place for reporting and handling such matters. More importantly, employees (and managers for that matter) need to be informed regarding how to protect themselves, as the members of an organization share responsibility for bringing about change in the culture of the workplace - and indeed for seeing that all are treated with respect. Organizations need not forbid social interactions among co-workers or employees, for a great deal of business is conducted over dinner or drinks. What is important is that all workers and managers remain professional, which of course, means that they never try to force themselves on others, whatever the genders of the individuals involved. It is also a fact of life that some romances begin in the workplace; proximity breeds attraction, and many workers spend nearly half of their waking hours on the job with their fellow workers.

Organizations have a clear responsibility to their employees and customers regarding SH. They cannot allow even a single documented incident to pass without reaffirming their values. Prompt action is required; simply having a policy on sexual harassment is insufficient defense for an organization in a court of law. Again, companies need to offer training for employees (Johnson, 2004). The actions of managers should be documented, and those who have fallen short in fulfilling their responsibilities relating to SH should be counseled and encouraged to attend diversity and/or sensitivity training. By documenting incidents of SH, offending parties can be made aware of the inappropriateness of their behavior and notified that further incidents might constitute grounds for dismissal. Diversity training can be useful in making managers aware of the importance of creating a sensitive workplace environment and serving as role models. Thus Dunlop and Lee (2004) were exactly right: when it comes to SH in organizations, a single bad apple can indeed be enough to spoil the entire barrel.

\section{References}

Aggarwal, A. P., \& Gupta, M. M. (2000). Sexual harassment in the workplace. (3rd ed.). Vancouver, BC: Butterworths. 


\section{SCENARIO-BASED TRAINING FOR SH PREVENTION}

Bainbridge, H. T., Perry, E. L., \& Kulik, C. T. (2018). Sexual harassment training: Explaining differences in Australian and US approaches. Asia Pacific Journal of Human Resources, 56(1), 124-147.

Barak, A. (1994). A cognitive-behavioral educational workshop to combat sexual harassment in the workplace. Journal of Counseling and Development, 72(6), 595-603.

Beauvais, K. (1986). Workshops to combat sexual harassment: A case study of changing attitudes. Signs: Journal of Women in Culture and Society, 12(1), 130-145.

Becton, J. B., Gilstrap, J. B., \& Forsyth, M. (2017). Preventing and correcting workplace harassment: Guidelines for employers. Business Horizons, 60(1), 101-111.

Blackman Legal Group. (2005). Employer policies. Retrieved July 7, 2006, from http: //www. blackmanlaw.com/california_sexual_harassment.asp

Blumenthal, J. A. (1998). The reasonable woman standard: A meta analytic review of gender differences in perceptions of sexual harassment. Law and Human Behavior, 22, 33-57.

Buchanan, N., Settles, I., Hall, T. A., \& O'Connor, R. (2014). A review of organizational strategies for reducing sexual harassment: Insights from the U.S. military. Journal of Social Issues, 70, 687-702.

Callanan, G. A., \& Perri, D. F. (2006). Teaching conflict management using a scenariobased approach. Journal of Education for Business, 81(3), 131-139.

Cheung, H. K., Goldberg, C. B., King, E. B., \& Magley, V. J. (2017). Are they true to the cause? Beliefs about organizational and unit commitment to sexual harassment awareness training. Group and Organization Management, 1-30.

Christian, V., \& Gumbus, A. (2009). Shades of gray: Applying professional codes of ethics to workplace dilemmas. Organization Management Journal, 6, 178-199.

Desplaces, D. E., \& Ogilvie, J. (2013). A Manager's action? An exercise for exploring sexual harassment. Organization Management Journal, 10(1), 36-44.

Dougherty, T. W., Turban, D. B., Olson, D. E., Dwyer, P. D., \& Lapreze, M. W. (1996). Factors affecting perceptions of workplace sexual harassment. Journal of Organizational Behavior, 489-501.

Dunlop, P. D., \& Lee, K. (2004). Workplace deviance, organizational citizenship behavior, and business unit performance: The bad apples do spoil the whole barrel. Journal of Organizational Behavior, 25(1), 67.

Ebner, N., \& Efron, Y. (2005). Using tomorrow's headlines for today's training: Creating pseudo-reality in conflict resolution simulation games. Negotiation Journal, 21, 377-394.

Gettman, H. J., \& Gelfand, M. J. (2007). When the customer shouldn't be king: Antecedents and consequences of sexual harassment by clients and customers. Journal of Applied Psychology, 92(3), 757-770.

Goldberg, C. B. (2011). What do we really know about sexual harassment training effectiveness? In A. Paludi, M. C. Paludi, \& E. DeSouza (Eds.), Praeger handbook on understanding and preventing workplace discrimination (Vol. 2) (pp. 45-48). Santa Barbara, CA: Praeger.

Festinger, L. \& Carlsmith, J. M. (1959). Cognitive consequences of forced compliance. Journal of Abnormal and Social Psychology, 58, 203-210. 


\section{SCENARIO-BASED TRAINING FOR SH PREVENTION}

Fitzgerald, L. F., Drasgow, F., Hulin, C. L., Gelfand, M. J., \& Magley, M. J. (1997). Antecedents and consequences of sexual harassment in organizations: A test of an integrated model. Journal of Applied Psychology, 82(4), 578-589.

Fitzgerald, L. E., Swan, S., \& Magley, V. J. (1997). But was it really sexual harassment? Legal, behavioral, and psychological definitions of the workplace victimization of women. In W. O'Donohue (Ed.), Sexual harassment: Theory, research and treatment (pp. 5-28). Boston, MA: Allyn and Bacon.

Johnson, M. W. (2004). Harassment and discrimination prevention training: What the law requires. Labor Law Journal, 55(2), 119.

Juzwik, M. M., Nystrand, M., Kelly, S., \& Sherry, M. B. (2008). Oral narrative genres as dialogic resources for classroom literature study: A contextualized case study of conversational narrative discussion. American Educational Research Journal, 45(4), 1111-1154.

Lucero, M. A. (2007). Using published arbitration decisions to develop teaching examples, cases and exercises. Organization Management Journal, 4(1), 43-51.

McLaughlin, H., Uggen, C., \& Blackstone, A. (2017). The economic and career effects of sexual harassment on working women. Gender and Society, 31(3), 333-358.

O’Connor, M., Gutek, B. A., Stockdale, M., Geer, T. M., \& Melancon, R. (2004). Explaining sexual harassment judgments: Looking beyond gender of the rater. Law and Human Behavior: Psychology, Law and the Workplace, 28(1): 69-95.

O’Leary-Kelly, A. M., Bowes-Sperry, L., Arens Bates, C., \& Lean, E. R. (2009). Sexual harassment at work: A decade (plus) of progress. Journal of Management, 35(3): 503-536

Paludi, M. A., \& Barickman, R. B. (1991). Academic and workplace sexual harassment: A resource manual. SUNY Press.

Quick, J. C., \& McFadyen, M. (2017). Sexual harassment: Have we made any progress? Journal of Occupational Health Psychology, 22(3), 286.

Rotondo, M., Nguyen, H., \& Sackett, P. (2002). A meta-analytic review of gender differences in perceptions of sexual harassment. Journal of Applied Psychology, 86(5), 914-922.

Salas, E., Wildman, J. L., \& Piccolo, R. F. (2009). Using simulation-based training to enhance management education. Academy of Management Learning and Education, 8(4), 559-573.

Sipe, S. R., Johnson, C. D., \& Fisher, D. K. (2009). University students' perceptions of sexual harassment in the workplace: A view through rose-colored lenses. Equal Opportunities International, 28(4), 336-350.

Strand, C. A., Welch, S. T., Holmes, S. A., \& Judd, S. T. (2002). Developing student abilities to recognize risk factors: A series of scenarios. Issues in Accounting Education, 17(1), 57-67.

Stockdale, M. S., Vaux, A., \& Cashin, J. (1995). Acknowledging sexual harassment: A test of alternative models. Basic and Applied Social Psychology, 17(4): 469-496.

Tatum, B. C., \& Eberlin, R. J. (2006). Organizational justice and conflict management styles: Teaching notes, role playing instructions, and scenarios. International Journal of Conflict Management, 17(1), 66-81.

Taylor, J. K. (1988). Sexual harassment: A non-adversarial approach. New York, NY: NYU Press. 


\section{SCENARIO-BASED TRAINING FOR SH PREVENTION}

Tyner, L. J., \& Clinton, M. S. (2010). Sexual harassment in the workplace: Are human resource professionals victims? Journal of Organizational Culture, Communication and Conflict, 14(1), 33-49.

U.S. Equal Employment Opportunity Commission. (2002). Facts About Sexual Harassment. Retrieved June 4, 2018, from https://www.eeoc.gov/facts/fs-sex.html

Williamson, E. (2006). Moving past hippies and harassment: A historical approach to sex, appearance and the workplace. Duke Law Journal, 56(2), 681-720.

Willness, C. R., Piers Steel, P., \& Lee, K. (2007). A meta-analysis of the antecedents and consequences of workplace sexual harassment. Personnel Psychology, 60(1), 127162.

Woodford, K. C., \& Woodford, T. J. (2005). Sudden-onset harassment: Negligence or strict 